\title{
Lymphopenia-induced proliferation in Aire-deficient mice helps to explain their autoimmunity and differences from human patients
}

\author{
Kai Kisand *, Pärt Peterson and Martti Laan \\ Molecular Pathology, Institute of Biomedicine and Translational Medicine, University of Tartu, Tartu, Estonia
}

\section{Edited by:}

Claudio Pignata, University of Naples

Federico II, Italy

Reviewed by:

Mitsuru Matsumoto, University of

Tokushima, Japan

Taishin Akiyama, University of Tokyo, Japan

Eliisa Kekäläinen, Karolinska

Institutet, Sweden

*Correspondence:

Kai Kisand, Molecular Pathology,

Institute of Biomedical and

Translational Medicine, University of

Tartu, Ravila 19, Tartu 50411, Estonia

e-mail:kai.kisand@ut.ee
Studies on autoimmune polyendocrinopathy candidiasis ectodermal dystrophy (APECED) and its mouse model - both caused by mutant AIRE - have greatly advanced the understanding of thymic processes that generate a self-tolerant T-cell repertoire. Much is now known about the molecular mechanisms by which AIRE induces tissue-specific antigen expression in thymic epithelium, and how this leads to negative selection of auto-reactive thymocytes. However, we still do not understand the processes that lead to the activation of any infrequent naïve auto-reactive T-cells exported by AIRE-deficient thymi. Also, the striking phenotypic differences between APECED and its mouse models have puzzled researchers for years. The aim of this review is to suggest explanations for some of these unanswered questions, based on a fresh view of published experiments. We review evidence that auto-reactive T-cells can be activated by the prolonged neonatal lymphopenia that naturally develops in young Aire-deficient mice due to delayed export of mature thymocytes. Lymphopenia-induced proliferation (LIP) helps to fill the empty space; by favoring auto-reactive T-cells, it also leads to lymphocyte infiltration in the same tissues as in day 3 thymectomized animals. The LIP becomes uncontrolled when loss of Aire is combined with defects in genes responsible for anergy induction and Treg responsiveness, or in signaling from the T-cell receptor and homeostatic cytokines. In APECED patients, LIP is much less likely to be involved in activation of naïve auto-reactive T-cells, as humans are born with a more mature immune system than in neonatal mice. We suggest that human AIRE-deficiency presents with different phenotypes because of additional precipitating factors that compound the defective negative selection of potentially autoaggressive tissue-specific thymocytes.

Keywords: AIRE, APECED, lymphopenia-induced proliferation, thymus, negative selection, autoantigens, immune privilege, NOD

\section{INTRODUCTION}

The autoimmune regulator (AIRE) is a transcriptional activator with a restricted expression pattern and important functions in medullary thymic epithelial cells (mTECs) (1). The thymus is the organ where a self-tolerant $\mathrm{T}$-cell repertoire is established via positive and negative selection of thymocytes. To ensure tolerance toward the set of tissue-specific antigens (TSAs) from different peripheral organs, mTECs "promiscuously" express thousands of TSAs that are then presented to developing thymocytes; one of the best known among them is insulin $(2,3)$. AIRE is the best characterized transcriptional regulator in mTECs. It is generally accepted that its main thymic role is to ensure negative selection of thymocytes with T-cell receptors (TCRs) with high affinities for epitopes from TSAs. At first sight, this idea seems to fit with the variety of endocrine, ectodermal, and lymphoid autoimmune diseases that present in patients with AIRE mutations and comprise the Autoimmune polyendocrinopathy candidiasis ectodermal dystrophy (APECED) or autoimmune polyendocrine syndrome type I (APS-I) syndrome (4-6). However, there is curiously little discussion about how these infrequent naive auto-reactive T-cells that escape negative selection in AIRE-deficient thymi are activated to cause disease in the periphery, or about the rather consistent early onset of its highly unusual cardinal manifestations, or about the strikingly different phenotypes in Aire ${ }^{-1-}$ mice (7-9). Table 1 lists the autoimmune features of AIRE-deficient humans vs. mice and highlights their surprisingly limited overlap (7-21). Here, we propose the hypotheses that defective thymic negative selection is not sufficient by itself to induce autoimmunity and that these differences in disease phenotypes reflect distinct varieties of additional influences in Aire ${ }^{-1-}$ mice vs. humans.

\section{AIRE IS RESPONSIBLE FOR NEGATIVE SELECTION OF TSA-SPECIFIC THYMOCYTES}

The normal roles of Aire in TSA up-regulation by mTECs, and thus in central tolerance induction, are firmly established. In mice transgenic for single TCRs specific for immune-dominant epitopes from hen egg lysozyme (HEL) or ovalbumin (OVA), large proportions of thymocytes are efficiently deleted if their neoself-antigens are expressed under Aire-dependent gene promoters. Membrane-bound HEL or OVA (mHEL or mOVA) under the rat 
Table 1 | Phenotypes and autoantibodies differ between APECED patients and Aire $^{-/-}$mice

\begin{tabular}{|c|c|c|c|}
\hline APECED patients ${ }^{a}$ & Aire $^{-l-}$ mice ${ }^{b}$ & APECED patients ${ }^{a}$ & Aire $^{-l-}$ mice ${ }^{b}$ \\
\hline \multicolumn{2}{|c|}{ DISEASES/IMMUNE CELL INFILTRATIONS } & \multicolumn{2}{|l|}{ AUTOANTIBODIESTO: } \\
\hline \multicolumn{2}{|l|}{ Chronic mucocutaneous candidiasis } & Type I IFNs & \\
\hline \multicolumn{2}{|l|}{ Addison's disease } & NALP5 & \\
\hline Ovarian failure & Infertility & CaSR & \\
\hline Autoimmune hepatitis & Liver infiltration & TG, TPO & \\
\hline \multicolumn{2}{|l|}{ Intestinal dysfunction } & TDRD6 & \\
\hline \multicolumn{2}{|l|}{ Pancreatitis } & AADC & \\
\hline \multicolumn{2}{|l|}{ Tubulointerstitial nephritis } & P450 1A2 & \\
\hline Interstitial lung disease & Lung infiltration & $\mathrm{TPH}$ & \\
\hline \multicolumn{2}{|l|}{ Asplenia } & KCNRG & \\
\hline \multicolumn{2}{|l|}{ Keratoconjunctivitis } & Myelin protein zero (12) & \\
\hline \multicolumn{2}{|l|}{ Dental enamel dysplasia } & LPLUNC1 (13) & Vomeromodulin (13) \\
\hline \multicolumn{2}{|l|}{ Nail dystrophy } & BPIFB1 (14) & BPIFB9 (14) \\
\hline \multicolumn{2}{|l|}{ Type 1 diabetes } & & OBP1a (16) \\
\hline \multicolumn{2}{|l|}{ Hypothyroidism } & & SVS2 (17) \\
\hline \multicolumn{2}{|l|}{ CIPD (10) } & & $\operatorname{IRBP}(15)$ \\
\hline \multirow[t]{4}{*}{ Pernicious anemia } & Gastritis & & alpha-fodrin (18) \\
\hline & Uveoretinitis & & TRP-1 (19) \\
\hline & Dacryoadenitis & & Mucin $6(20)$ \\
\hline & Salivary gland infiltration & & \\
\hline
\end{tabular}

${ }^{a}$ Autoimmune phenotypes of APECED patients and their autoantibody reactivities are summarized from (21).

${ }^{b}$ Summarized from (9), only Aire ${ }^{-/}$mice on C57BL/6 and BALBC backgrounds without additional immune defects are included.

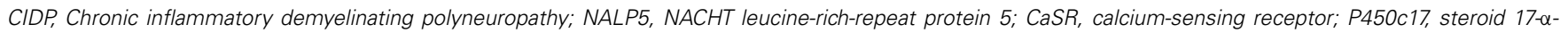

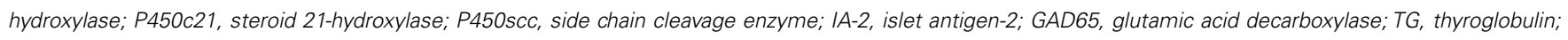

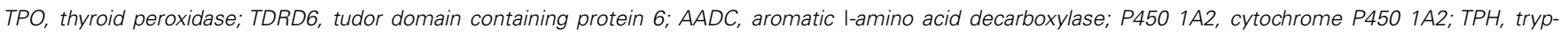

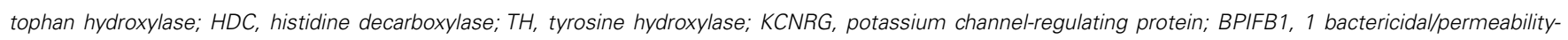
increasing fold-containing B1; OBP1a, odorant binding protein 1a; SVS2, seminal vesicle secretory protein 2; IRBP, interphotoreceptor retinoid-binding protein; TRP-1, tyrosinase-related protein-1; LPLUNC1, Long palate lung nasal epithelium clone.

Shared autoimmune features are indicated in bold.

insulin promoter (RIP) is expressed in both pancreatic $\beta$ cells and the thymus $(22,23)$, and mHEL under the interphotoreceptor retinoid-binding protein (IRBP) promoter in both retina and thymus (24). When these mice are crossed with the respective TCRtransgenic animals, their clonotypic thymocytes are deleted with $75-97 \%$ efficiency, but only in mice with intact Aire, highlighting its indispensable role in negative selection. Moreover, the prevalence of neo-self-antigen-reactive T-cells is reduced still further in the periphery, underlining the importance of active peripheral tolerance mechanisms.

Interestingly, expression levels of the transgenes in the thymus varied in different studies. In a retinal neo-self-antigen model, the transgenic mRNA (Escherichia coli $\beta$-galactosidase under arrestin promoter) was undetectable even in the wild-type (wt) thymus (25). Whereas mHEL showed the expected Aire-dependent pattern of higher expression in wt than Aire $e^{-/-}$mTECs $(24,26)$ (when driven by the insulin or IRBP promoters), transcript levels for RIPdriven mOVA were not markedly decreased in Aire ${ }^{-l-}$ thymi (22). This raises the possibility that, besides up-regulation of TSAs in the thymus Aire plays additional roles in generating self-tolerance, e.g., inducing the maturation of mTECs, as reviewed recently $(27,28)$. Loss of Aire also alters thymic architecture and mTEC ultrastructure $(29,30)$, and these effects reach back even to the immature Aire-negative mTEC subset (31). Indeed, there are reports that Aire-deficiency leads to breakdown of tolerance even to apparently Aire-independent antigens (18). Moreover, the development of the most mature single $\mathrm{CD} 4$ positive thymocyte subpopulation $\left(\mathrm{CD}^{-} 9^{-}, \mathrm{Qa}-2^{+}\right)$is impaired in Aire-deficient thymi (32).

The role of Aire in negative selection has also been studied in TCR-transgenic models where clonotypic T-cells are targeted 
toward naturally expressed self-antigens such as the melanocyte/melanoma-specific tyrosinase-related protein-1 (TRP-1). In these mice (on a $\mathrm{Rag}^{-1-}$ background), negative selection again depended on Aire; when its only change was the dominant negative Aire G228W point mutation, melanoma growth was decreased. Surprisingly, however, vitiligo was not reported in this study, although TRP-1 is also expressed in normal melanocytes (19).

The role of Aire in negative selection has also been studied in another TCR-transgenic model with reactivity to the major retinal autoantigen - IRBP. Although its thymic expression is reportedly Aire-dependent, clonotypic thymocytes were not deleted in any of three transgenic mouse lines on the uveitis-susceptible B10.RIII background (33). On the contrary, in two of them, the majority of CD4 single positive thymic T-cells bound IRBP-MHC dimers; strikingly they were several-fold more frequent than in wt animals (33). Uveitis developed spontaneously in these two mouse lines, but not in the third, where frequencies were lowest in both thymus and periphery: 6 and 1\% respectively; those were still much higher than in Aire ${ }^{-1-}$ mice with no TCR-transgene (34). Clonotypic Tcell deletion was also incomplete in mice transgenic for an insulin $\mathrm{B}$ chain epitope-specific TCR, only a fraction of which developed diabetes (35).

Several studies have confirmed the importance of thymic negative selection of auto-reactive T-cells in physiological settings, i.e., in mice with un-manipulated T-cell repertoires $(34,36)$. Indeed, thymic stromal or lymphoid cells were necessary to confer tolerance to the central nervous system (CNS) antigen myelin proteolipid protein (PLP) (36). Importantly, susceptibility to experimental autoimmune encephalomyelitis (EAE) in SJL/J mice could be explained by the exclusion of the immunodominant epitope of PLP (for this strain) from the thymic isoform of PLP, and the export of potentially auto-reactive cells to the periphery (36). However, this model of EAE in SJL/J mice does not develop spontaneously, but requires immunization with antigen emulsified in complete Freund's adjuvant (CFA).

\section{NAIIVE AUTO-REACTIVE T-CELLS DO NOT CAUSE AUTOIMMUNITY BY DEFAULT}

According to current models, AIRE's main role is to ensure negative selection of TSA-specific thymocytes. If so, self-reactive T-cells escaping from Aire ${ }^{-l-}$ thymi must normally be naïve and infrequent. Even when frequencies are much higher in TCR-transgenic models, disease penetrance is not always $100 \%$, especially when the TCRs are expressed in CD4+ T-cells. In the TCR-TrpHEL model, with neoantigen expression in melanocytes, $12 \%$ of the animals remained free of vitiligo (37); in an RIP-OVA OTII model with neo-self-antigen expression in pancreatic $\beta$-cells, about $1 / 3$ were persistently non-diabetic (23) in spite of large numbers of auto-reactive T-cells in the periphery. TSA-specific T-cells are much less frequent in Aire ${ }^{-1-}$ animals with un-manipulated Tcell repertoires. How their uncommon naïve thymic emigrants are activated to induce autoimmune disease in the periphery remains unexplained, one might expect them to get tolerized instead (38, 39). Indeed, when naïve T-cells encounter self-antigen in tissuedraining lymph nodes or spleen in wt mice, they undergo an initial burst of proliferation that is followed by deletion and anergy (4044 ) or acquisition of regulatory T-cell (Treg) phenotypes $(35,45)$.
In intriguing contrast, autoimmunity readily develops when naïve auto-reactive T-cells are transferred to lymphopenic hosts $(46,47)$.

LYMPHOPENIA TRIGGERS AUTOIMMUNITY IN AIRE-I- MICE The striking similarities in manifestations in Aire ${ }^{-l-}$ and day 3 thymectomized mice ( $\mathrm{d} 3 \mathrm{tx}$ ) have been noticed earlier (48-50). Both models show inflammatory infiltrates in similar tissues plus autoantibodies against some of their antigens in: stomach, thyroid, ovaries, prostate, pancreas, lacrimal and salivary glands, and testis $(9,18,50-55)$. With both types of models, the manifestations even follow the same strain-specific preferences: e.g., generally lower autoimmune susceptibility in $\mathrm{C} 57 \mathrm{BL} / 6$ mice, whereas gastritis is the most prevalent feature on the BALBc background.

In $\mathrm{d} 3 \mathrm{tx}$ mice, the autoimmunity is explained by prolonged lymphopenia-induced proliferation (LIP) of auto-reactive lymphocytes that out-compete Tregs in susceptible animals $(56,57)$. Although normal neonatal mice show a physiologic lymphopenia, it does not induce substantial LIP (56). We have shown that, besides inducing TSA expression, thymic Aire normally upregulates several chemokines, especially CCR7 and CCR4 ligands, that attract immature thymocytes to the medulla. Their corticomedullary migration is delayed in Aire ${ }^{-1-}$ mice, and that, in turn, delays the export of their mature progeny, prolonging the postnatal lymphopenia at least through day 5 (31). Interestingly, mice deficient in CCR7 (or its ligands) show not only similar delays in Tcell emigration from the thymus but also inflammatory infiltrates in the very organs listed above (58-60). We therefore hypothesize that LIP also contributes to these inflammatory infiltrates and compensates for the relatively low numbers of naïve auto-reactive T-cells that escape from Aire ${ }^{-/-}$thymi. This notion is supported by the evidence that the lymphopenia in irradiated Aire ${ }^{-/-}$mice increases the gastric autoimmunity (20); and that Aire expression is required only in the fetal and early post-natal periods to prevent autoimmunity (48).

Lymphopenia-induced proliferation is sometimes classified according to the rate of division of T-cells to homeostatic and spontaneous proliferation (56). It is highest when chronically lymphopenic adult mice are reconstituted with low numbers of lymphocytes $(56,61)$. In this case, T-cells respond to antigens derived from commensals, which probably translocate from the gut to lymphoid organs due to the host immunodeficiency (61). Commensals seem unlikely contributors to the LIP that occurs early in life, e.g., in d3tx mice. Nevertheless, LIP favors autoreactive cells, as they get stronger signals through their TCRs as well as from homeostatic cytokines (IL-7 and IL-15) that are upregulated in lymphopenic hosts. As they concomitantly differentiate, these T-cells acquire the markers of activated memory cells $\left(\mathrm{CD} 44^{+} \mathrm{CD} 6 \mathrm{~L}^{-}\right)(62-66)$.

There are several indications of homeostatically proliferating T-cells in Aire ${ }^{-l-}$ mice, including signs of oligoclonality (67). Whereas thymocytes from Aire-deficient and wt mice showed no differences in TCR V $\beta$-chain CDR3 length and spectratype, splenic T-cells from Aire ${ }^{-1-}$ mice showed a clear alteration in the TCR repertoire distribution in 3 out of $24 \mathrm{~V} \beta$ families at 2 and 6 months of age (67). A more recent study also found slight perturbations in CDR3 V $\beta$ length distribution, and significantly higher percentages of CD44+ T helper cells in spleens and lymph nodes of Aire $e^{-1-}$ 
mice than in wt controls (9). CD44 up-regulation in T-cells from Aire $^{-1-}$ mice was also noted by Anderson et al. (68).

Looking for further activation of auto-reactive cells in lymphopenic conditions, Kekalainen et al. (69) transferred lymph node cells from Aire ${ }^{+}$and Aire ${ }^{-1-}$ mice to immunodeficient hosts. However, although especially the CD8+ Aire ${ }^{-1-}$ T-cells proliferated more, there was no clinical disease, and the mild infiltrates in the livers, salivary glands, and pancreata did not differ from those in the controls. The rare auto-reactive cells in these animals had probably already been tolerized by peripheral mechanisms in the donors themselves. This suggests that prolonged lymphopenia in the neonatal period, together with export of naïve cells to the periphery, contributes substantially (but not exclusively) to the development of inflammatory infiltrates in Aire ${ }^{-l-}$ mice, and that the auto-reactive cells are subject to regulation in the periphery that prevents serious damage to the target organs.

Certain TCR-transgenic T-cells are also prone to homeostatic proliferation. These include the MHC-class I-restricted OT-I line recognizing a peptide from OVA (62). Interestingly, spontaneous diabetes already appears in neonatal RIP-OVA Aire ${ }^{-l-}$ OT-I mice (22). This severe autoimmunity might well have been potentiated by perinatal activation of the transgenic T-cells in these lymphopenic hosts.

\section{AIRE AND LIP IN AUTOIMMUNITY AGAINST PRIVILEGED ORGANS}

Autoantigens from some organs like the CNS/retina were thought to be sequestered from the immune system, which might therefore not be fully tolerant to them. It has been suggested that AIRE might play especially important roles in protecting these organs from autoimmune attack, e.g., provoked by local infections (49). Indeed, central deletion of auto-reactive thymocytes would be a particular priority for CNS and eye antigens, as regeneration is minimal in these tissues, and their peripheral tolerizing mechanisms might be inefficient. The intraocular compartments are isolated from the circulation - by barriers formed by tight junctions between the endothelial cells of the ciliary blood vessels, and between the lining epithelial cells; also in the retinal pigment epithelium (RPE) and the local endothelium (70-72). These barriers are impermeable to circulating soluble macromolecules and most cell types except for activated T-cells and immature antigenpresenting cells (APCs). In the other direction, any soluble retinal antigens (such as IRBP) shed physiologically or injected experimentally can drain via the aqueous fluid and episcleral veins to reach the thymus, liver, and spleen (70). The resulting systemic tolerance is termed anterior chamber-associated immune deviation (ACAID). The presumed privilege of the eye used to be attributed to paucity of APCs and lymphatics, but it is now known that there are rich networks of APCs and a functioning lymphatic system draining all parts of the eye, except the retina proper, via the submandibular node (70-72). Thus, ocular privilege is not due to a passive barrier, but instead depends on inducible active processes that can be transferred by immune cells.

One prominent feature in Aire ${ }^{-1-}$ mice is their retinal disease. Although it is extremely rare in APECED patients who frequently suffer from keratito conjunctivitis $(4,73)$, it affects $\sim 30 \%$ of these mice by age 20 weeks on a C57BL/6 background (34). Recently, they were backcrossed onto the autoimmune uveitis-susceptible B10.RIII background to monitor eye pathology more carefully (74). Surprisingly, the spontaneous disease was milder on the Aire ${ }^{-1-}$ background than in the other two models (induced by immunization with IRBP + CFA or arising spontaneously in IRBP TCR-transgenic mice), and rarely caused blindness. Instead, it presented with relatively low-grade but multi-focal retinal inflammation and severe choroiditis, possibly hinting at moderately potent regulatory mechanisms.

There are many indications that EAU is enhanced by LIP of selfreactive T-cells $(33,75,76)$. In intact wt recipients, IRBP-transgenic T-cells only induced uveitis after antigen-activation: recipients of naïve cells, even from the highest transgenic TCR-expressing line, remained disease-free. In telling contrast, naïve T-cells did induce disease when transferred to lymphopenic $\mathrm{Rag}^{-1-}$ recipients, again implicating LIP in converting them into effector cells (33). In the same study, LIP was evidenced in the mouse lines with higher prevalences of TCR-transgenic T-cells by increases in $\mathrm{CD} 44^{+} \mathrm{CD} 62 \mathrm{~L}^{-}$activated T-cells, even in peripheral lymph nodes that do not drain the eye. This implicates LIP in these transgenic animals too, possibly due to aberrant thymic development, and probably lymphopenic periods earlier in life (33). LIP has also been identified as a potent activator of EAU in another transgenic model (76) and, interestingly, uveoretinitis develops in unimmunized d3tx mice if subsequently injected with anti-CD25 to deplete $\mathrm{CD} 25^{+} \mathrm{CD} 4^{+}$Tregs (75).

\section{REVERSAL OF LYMPHOPENIA ALLEVIATES AUTOIMMUNITY}

Autoimmunity that results from LIP should be down-modulated by transfer of lymphocytes. This indeed occurs in Aire ${ }^{-1-}$ mice, where the appearance of inflammatory infiltrates could be suppressed by introducing a controlled excess of T-cells from normal donors - by co-transplanting 1:4 mixes either of Aire ${ }^{-l-}$ : wt stroma from thymic lobes, or of splenocytes, into athymic or $\mathrm{Rag}^{-1-}$ recipients, respectively (22).

As the phenotypes of Aire ${ }^{-l-}$ mice are so mild, it is difficult to dissect the mechanisms that might be modulating their autoimmunity. Therefore, crosses of Aire ${ }^{-l-}$ with NOD mice have been used, as they develop earlier and more severe autoimmunity (48). In these crosses, Aire expression is especially important during perinatal life. Moreover, intraperitoneal injection of adult T-cells on days 1 and 7 conferred significant but not complete protection from this exaggerated autoimmunity (48) (see below).

\section{IS ABSENCE OF SELF-ANTIGEN FROM THE THYMUS SUFFICIENT BY ITSELF TO INDUCE ORGAN-SPECIFIC AUTOIMMUNE DISEASE?}

It is sometimes assumed that the autoimmunity results solely from the absence of a single autoantigen from the thymus in the presence of wt Aire. That is apparently contradicted by our hypothesis that prolonged lymphopenia in Aire ${ }^{-1-}$ mice is an important cofactor for auto-aggression, so we now discuss two models that might help to distinguish between these possibilities.

DeVoss et al. identified IRBP as the major target in autoimmune uveitis in Aire $^{-1-}$ mice (15). Its thymic expression is Airedependent, although it is barely detectable in wt thymic stroma. Absence of IRBP in the thymic compartment alone was sufficient 
to cause disease when athymic nude mice were transplanted with fetal thymic stroma from IRBP $^{-/-}$mice or wt mice. Mononuclear infiltrates appeared in their retinae, but not in recipients of wt stroma. Here again, lymphopenia must have been an important early contributor, as the first thymic emigrants appeared to abnormal lymphopenic adults.

When DeVoss et al. also crossed Aire ${ }^{-1-}$ with $\mathrm{IRBP}^{-1-}$ mice, the retinae showed no infiltrates, as expected because there was no target for the IRBP-specific cells to attack. However, IRBP is secreted, and even reaches the vitreous, and eventually drains to the spleen and lymph nodes (77). Hence this major eye retinal autoantigen was missing from the peripheral immune system too, and was not available to fuel homeostatic proliferation of IRBPspecific T-cells. Also the IRBP ${ }^{-/-}$retina is atrophic and might be depleted of other autoantigens.

Interestingly, when mice transgenic for mHEL under the IRBP promoter were crossed with HEL-specific TCR-transgenic mice, they showed severe spontaneous EAU even on a wt Aire background (24). Negative selection of clonotypic T-cells was not complete in this model, and many neo-self-antigen-specific Tcells were exported to the periphery. The mHEL - unlike soluble IRBP itself - may have failed to access lymphoid organs/induce peripheral tolerance. The resulting disease was already so severe that any exacerbating effect of Aire-deficiency was not detectable. If these HEL-specific clonotypic T-cells were susceptible to LIP due to cross-reactivity with some self epitopes (which has not been checked), that might well have contributed too.

In another study, mice were engineered specifically to prevent any insulin expression in mTECs, and to use only one of the two insulin genes (Ins2) in their pancreatic $\beta$-cells (78). They developed spontaneous diabetes within 3 weeks after birth. However, there are also some caveats with this study (79). The diabetes was not transferrable to immunodeficient adult hosts with lymphocytes or thymi from the transgenic mice, which showed only moderate insulitis (80). This apparently implicates the additionally impaired physiology of Ins $1^{-1-} \beta$-cells (compensatory hyperplasia, increased death during the developmental wave of apoptosis that occurs in normal development) in disease initiation in very young mice (81). In this model again, loss of thymic negative selection alone was not sufficient to cause clinical disease. Furthermore, since insulin is already secreted in the fetus, it should normally be available for thymic deletion, e.g., when presented by medullary dendritic cells, without promiscuous expression in mTECs, but its levels may be decreased prenatally in $I n s 1^{-1-}$ mice, reducing its availability for negative selection.

\section{AIRE-DEFICIENCY BECOMES LETHAL IF PERIPHERAL BACK-UP MECHANISMS ARE ELIMINATED}

Two highly informative crosses of Aire ${ }^{-/-}$mice - with strains with other immune defects - underline the importance of backup mechanisms that are apparently responsible for the mildness of the disease phenotypes in Aire $e^{-1-}$ mice. Crosses onto Cbl- $b$ deficient or diabetes-prone NOD backgrounds show astonishing similarities $(39,53,82)$. They both suffer from early wasting disease and succumb to acute exocrine pancreatitis around 3-4 weeks of age. Aire ${ }^{-1-} / C b l-b^{-1-}$ mice showed additional lymphocytic infiltrates in submandibular salivary glands and stomach (39), while
Aire-deficiency on the NOD background was accompanied by severe pulmonitis and infiltrates in liver, salivary gland, prostate, ovary, stomach, and thyroid $(53,82)$.

Interestingly, mice deficient in Cbl-b alone are healthy in the absence of additional triggers (83), so it was a major surprise that crossing with Aire ${ }^{-1-}$ mice led to such severe disease. Cbl-b normally renders naïve T-cells highly dependent on co-stimulation; when it is deleted, they are "trigger-happy," and much less susceptible to anergy. Clonal deletion of CD8+ T-cells also depends on Cbl-b, and Cbl-b-deficient T-cells are partially resistant to Treg cell-mediated suppression (83). Furthermore, induction of Tregs from naïve precursors is likewise impaired in the absence of Cbl-b (84).

The CD44+ memory phenotype T-cells generated by LIP are normally restrained by Tregs that proliferate rapidly in $\mathrm{d} 3 \mathrm{tx}$ mice and are crucial for preventing autoimmunity in lymphopenic animals $(50,85)$. In Aire $e^{-l-} / C b l-b^{-1-}$ mice, readier activation of homeostatically proliferating T-cells, impaired induction of peripheral Tregs and lower responsiveness of proliferating lymphocytes to the influence of Tregs are probably responsible for their severe early autoimmunity. The proportions of CD4+ and CD8+ T-cells with CD44 $4^{\text {high }}$ were greatly increased in these double knock-outs. This supports the idea that LIP is participating during prolonged lymphopenia in Aire ${ }^{-/-}$mice, where "trigger-happy" polyclonal T-cells proliferate in response to available self-peptide-MHC complexes in the presence of homeostatic cytokines.

Interestingly, the immune defects in NOD mice include mild lymphopenia and dysregulated function of homeostatic cytokines (46). Indeed, T-cell transfer and CFA injection protect NOD mice against diabetes (46). The efficiency of their thymic selection has been a matter of controversy; recent data are in line with normal negative selection but impaired positive selection in NOD mice due to selective defects in the Erk1/2 signaling module downstream of TCR (86) that is important for T-cell survival and tuning of TCR responsiveness. In the periphery, anergy induction appears normal in NOD T-cells. Insulin-specific effector T-cells were generated in pancreatic lymph nodes only between 3 and 5 weeks of age, at the time of increased release of $\beta$-cell antigens (87). In all mouse strains, a wave of $\beta$-cell apoptosis occurs during the neonatal period, peaking at 9-15 days, but apoptotic debris is cleared less efficiently in NOD mice (88). Interestingly, diabetes is accelerated in mice thymectomized at week 3 - i.e., precisely when $\beta$-cell-specific T-cells are initially activated - when Tx caused moderate lymphopenia. Furthermore, the timing of that lymphopenia is evidently critical in target organ selection; while d3tx in NOD mice did not affect diabetes incidence, gas-

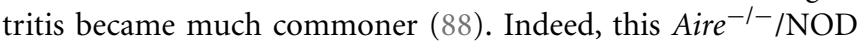
combination may maximize homeostatic proliferation just when exocrine pancreatic antigen release is greatest. The combination of impaired positive selection in NOD mice with delayed migration of thymocytes into the Aire ${ }^{-l-}$ medulla apparently amplifies the neonatal lymphopenia, which is further exaggerated by hyper-responsiveness of NOD T-cells to IL-21 and poor T-cell survival. Homeostatically proliferating cells compete for IL-7 and/or available $\mathrm{MHC} /$ (cross-reactive) self peptides (56). Therefore the absence of diabetes in Aire -l- $^{-/ N O D}$ mice may implicate the early 
proliferation of T-cells that encounter other available autoantigens and fill the space before the $\beta$-cell antigens are released.

Why the autoimmune attack focuses on the exocrine pancreas remains obscure. We suggest that three peculiarities of neonatal mice might be relevant: (1) readier access of neonatal T-cells to peripheral organs (89) where they normally differentiate into TSA-specific Tregs (45). Interestingly, this conversion to Tregs is subverted by IL-7 (45); (2) rapid changes and increased blood flow to certain organs (lungs, pancreas, liver, and intestine) after birth that renders their antigens more accessible to T-cells; (3) autophagy that is naturally upregulated immediately after birth to adapt to the loss of the constant trans-placental supply of nutrients - especially in muscle/diaphragm, heart and lungs; also the pancreas, which undergoes major changes after birth too, to meet the demands for the proteolytic enzymes it must now secrete (90). Their premature intracellular activation in autophagolysosomes, together with autoimmune attack by "trigger-happy" homeostatically proliferating T-cells, might greatly exacerbate the tissue damage. The thymic involution in Aire $e^{-1-} / C b l-b^{-1-}$ mice could be the result of stress or a "cytokine storm" created by this fulminant pancreatic disease.

\section{TREG CELLS IN AIRE-DEFICIENCY}

Studies in APECED patients have shown significantly lower Treg numbers and function than in healthy controls (91-94). Whether this is a direct effect of the thymic AIRE-deficiency or secondary to the severe autoimmune diseases in these patients remains unknown. By contrast, the role of Aire-deficiency in the development of Treg cells in the mouse thymus is controversial. Many studies have reported that their numbers are unchanged $(9,18,26$, 95), but others have found them reduced $(22,96,97)$. In peripheral organs, their numbers and function are similar to those in wt mice $(9,22)$. Recently, Malchow et al. showed appearance of Tregs specific for an Aire-dependent TSA that proliferated in tumors and could therefore interfere in their rejection (96). The autoimmunity in $\mathrm{d} 3 \mathrm{tx}$ mice was initially thought to arise because of significantly later maturation and release of Tregs than of effector cells (55). However, Tregs proliferate equally well in $\mathrm{d} 3 \mathrm{tx}$ lymphopenic hosts, which is important in the prevention of autoimmunity $(50,64)$. Interestingly, LIP is even greater in Tregs from Aire ${ }^{-/-}$than wt mice when transferred to lymphopenic hosts (69).

One of the crosses that showed no additive effect on the phenotype of Aire ${ }^{-1-}$ mice was with Card11 1unm/unm (39). Normally, Card 11 acts in the NFKB module of TCR-signaling, and this mutation leads to impaired Foxp3+ Treg differentiation in the thymus, 6-7 times fewer peripheral Tregs, and a gradual increase in Th2 cells (98). Interestingly, however, in Aire ${ }^{-1-}$ mice, these low-frequency Tregs could still reduce tissue infiltration. Furthermore, while Tregs are crucial for controlling autoimmunity against several organs, they seem to play no prominent role in eye disease: FoxP3-mutant scurfy mice do not develop spontaneous uveitis, suggesting that other tolerance mechanisms are more important than Tregs in protecting against retinal autoimmunity.

Also very informative are the crosses of B6.Foxp $3^{\text {sf }}$ mice (with the null "scurfy" Foxp3 gene mutation) onto the Aire ${ }^{-1-}$ mice or NOD genetic backgrounds (99). The $S f$ mutation by itself causes characteristic skin disease, massive lymphoproliferation, and infiltration most severely in the liver, but also the lungs and exocrine pancreas $(100,101)$. The crosses onto both backgrounds started to develop more severe lung and liver infiltrates much earlier and died significantly younger than B6.Foxp $3^{\text {sf }}$ mice (99). While there were no changes in the infiltrates characteristically seen in other organs in B6.Foxp $3^{\text {sf }}$ mice, those typical of Aire -1- $^{-1}$ mice on the C57BL/6 background (in the eyes, salivary glands) were-surprisingly-not seen in the B6.Foxp $3^{\text {sf }}$ Aire-deficient mice. Moreover, phenotypes were identical in $s f$ mutant mice on these Aire $^{-1-}$ and NOD backgrounds; to us, that implicates prolonged neonatal LIP rather than deficiency in thymic negative selection in this aggravated pathology in both crosses. $S f$ mutant Tregs are evidently not able to limit the activation of homeostatically proliferating T-cells. This is also illustrated by the similar wasting disease (with infiltrates in lungs, liver, pancreas, and stomach) in a model where neonatal T-cells are unable to respond to TGF- $\beta$ signaling (102).

\section{WHAT IS TRIGGERING AUTOIMMUNITY IN APECED PATIENTS?}

If the mild phenotypes in Aire ${ }^{-l-}$ mice are in line with the requirements for pathogenic T-cell activation, why are the phenotypes so much more severe in APECED patients? In humans too, it seems very unlikely that defective negative selection is the only cause of the severe autoimmune destruction of endocrine glands and other tissues $(6,21,103)$. We are born with a much more mature immune system than mice $(104,105)$. Although lymphocyte function is under-developed in neonates, their numbers per milliliters of blood are even higher than in adult humans. Therefore, even if thymocyte migration is delayed because of impaired chemokine secretion by AIRE-deficient mTECs in the human fetus, this is probably compensated by the longer gestation. Neonatal lymphopenia has not been studied in APECED because the disease is usually diagnosed much later. Interestingly though, adult APECED patients have increased IL-7 concentrations in their sera that may be related to impaired T-cell homeostasis (106). The clear differences in disease phenotypes between APECED patients and Aire ${ }^{-1-}$ mice suggest separate precipitating factor(s) in humans. These remain unidentified, but the surprisingly similar autoantibodies in patients with APECED and thymoma make any contribution from lymphopenia in human AIRE-deficiency seem even less likely (107). Nevertheless, the same logic - that additional activation is required before the rare naïve auto-reactive cells that escape from human AIRE-deficient thymi/thymomas can induce autoimmune disease - must apply in humans too $(6,103)$. In APECED, CMC, hypoparathyroidism, and Addison's disease sometimes present even at 2-3 years of age (4). Evidently, T-cells must go onto attack very soon after birth to destroy sufficient tissue to cause disease so soon; to us, that argues against any need for environmental triggers. Moreover, the first targets of the autoimmune attack are not AIRE-dependent TSAs (21). We propose that the pathogenic T-cells are already primed before their export from AIRE-deficient thymi or thymomas. A study on T-cells in APECED adults has shown gross alterations, especially in the CD8+ population, that include increased proliferation, lower expression of both IL-7R and the negative regulator of TCR-signaling CD5, and also absence of the regular naïve $\mathrm{T}$-cell compartment, relative to 
age-matched healthy controls (106). That could be secondary to the autoimmune diseases in APECED, a possibility that could be tested by assessing the activation of recent thymic emigrants before onset of APECED in pre-symptomatic young siblings of known patients.

In APECED, autoantibodies neutralizing type I IFNs and IL-22 can reach high titers even by 7 months of age, when autoantibodies to steroidogenic enzymes may also start to appear (108). Moreover, these autoantigens are produced in the thymus by cell types other than mTECs, so they should be available for negative selection even when AIRE is deficient (103). To explain these peculiarities, we have suggested biased selection or active autoimmunization in human thymi rendered "dangerous" by AIRE-deficiency (21, 103). That even leads to other secondary lymphoid tissue behavior in thymomas such as spontaneous production of anti-IFN- $\alpha$ and IL-12 autoantibodies by terminal plasma cells in sero-positive patients (109).

\section{FURTHER PREDICTIONS}

If gastritis in BALBc mice and EAU in B10.RIII mice are caused by LIP, they should be ameliorated by blocking homeostatic cytokines postnatally and simultaneously transferring lymphocytes into the lymphopenic hosts. As these cytokines sensitize TCRs through induction of pERK1/2, its inhibitors could be tested instead (65).

The phenotype of Cbl-b- and Aire double deficient mice could be mimicked by crossing with other mutant mouse strains with impaired T-cell susceptibility to anergy induction, or by thymectomizing $C b l-b^{-1-}$ mice on days $1-3$.

Curiously, autoimmunity is more often related to lower than higher TCR-signaling, perhaps because of weaker peripheral tolerance $(65,86)$. During their development, cortical thymocytes are positively selected when their receptors are triggered by selfpeptide-MHC complexes. These so called "tonic" signals are also needed for T-cell survival in the periphery, but they are regulated to remain just below the threshold for activation and proliferation (62). When TCR-signaling is impaired, the cells have to adapt to respond to weaker signals, which makes them more responsive to self-antigens, e.g., during periods of over-production of homeostatic cytokines. Theoretically, crosses of Aire ${ }^{-1-}$ mice onto backgrounds with decreased TCR-signaling and reduced T-cell survival could lead to phenotypes similar to those in Aire $^{-l-} \times \mathrm{NOD}$ crosses.

\section{SUMMARY}

It is unlikely that defective negative selection of auto-reactive thymocytes in AIRE-deficient thymi is the only cause of the associated autoimmune diseases in either model mice or APECED patients. Naïve T-cells require activation before they can cause tissue destruction: in uninfected neonates with no danger signals, tolerization by peripheral mechanisms seems a much likelier outcome. A hitherto under-recognized feature of Aire ${ }^{-1-}$ mice is their prolonged neonatal lymphopenia: by inducing LIP, it favors the proliferation and activation particularly of auto-reactive T-cells. This also helps to explain the strikingly similar phenotypes of lymphopenic day 3 thymectomized and Aire ${ }^{-l-}$ mice. However, the many developmental (ontogenetic) differences make LIP seem a much less likely contributor in humans - where we propose that additional mechanisms promote the early and much more sharply focused autoimmune attack on such unusual targets as the parathyroids, steroidogenic tissues/enzymes, and cytokines.

The mouse model has been extremely valuable in demonstrating Aire's role in negative selection of auto-reactive thymocytes. However, the differences in pathogenetic mechanisms and in autoimmune phenotypes in APECED patients question its suitability for testing new treatment options, and imply that merely restoring thymic TSA expression might not be enough to halt the autoimmunity in the patients. They also emphasize the importance of studies in human subjects, and again underline the need for caution when extrapolating from mouse models.

\section{ACKNOWLEDGMENTS}

We are grateful to our good friends and colleagues Nick Willcox and Tõnis Org for inspiring discussions over the years. Our special thanks go to Nick for his generous help in editing the manuscript. The study was supported by the Estonian Research Council grant IUT2-2, European Regional Development Fund, and Archimedes Foundation.

\section{REFERENCES}

1. Peterson P, Org T, Rebane A. Transcriptional regulation by AIRE: molecular mechanisms of central tolerance. Nat Rev Immunol (2008) 8:948-57. doi:10.1038/nri2450

2. Kyewski B, Klein L. A central role for central tolerance. Annu Rev Immunol (2006) 24:571-606. doi:10.1146/annurev.immunol.23.021704.115601

3. Klein L, Hinterberger M, Wirnsberger G, Kyewski B. Antigen presentation in the thymus for positive selection and central tolerance induction. Nat Rev Immunol (2009) 9:833-44. doi:10.1038/nri2669

4. Husebye ES, Perheentupa J, Rautemaa R, Kampe O. Clinical manifestations and management of patients with autoimmune polyendocrine syndrome type I. J Intern Med (2009) 265:514-29. doi:10.1111/j.1365-2796.2009.02090.x

5. Kluger N, Ranki A, Krohn K. APECED: is this a model for failure of T cell and B cell tolerance? Front Immunol (2012) 3:232. doi:10.3389/fimmu.2012.00232

6. Arstila TP, Jarva H. Human APECED; a sick thymus syndrome? Front Immunol (2013) 4:313. doi:10.3389/fimmu.2013.00313

7. Kekalainen E, Miettinen A, Arstila TP. Does the deficiency of Aire in mice really resemble human APECED? Nat Rev Immunol (2007) 7:1. doi:10.1038/ nri2136-cl

8. Pontynen N, Miettinen A, Arstila TP, Kampe O, Alimohammadi M, Vaarala $\mathrm{O}$, et al. Aire deficient mice do not develop the same profile of tissuespecific autoantibodies as APECED patients. J Autoimmun (2006) 27:96-104. doi:10.1016/j.jaut.2006.06.001

9. Hubert FX, Kinkel SA, Crewther PE, Cannon PZ, Webster KE, Link M, et al. Aire-deficient C57BL/6 mice mimicking the common human 13-base pair deletion mutation present with only a mild autoimmune phenotype. J Immunol (2009) 182:3902-18. doi:10.4049/jimmunol.0802124

10. Valenzise M, Meloni A, Betterle C, Giometto B, Autunno M, Mazzeo A, et al. Chronic inflammatory demyelinating polyneuropathy as a possible novel component of autoimmune poly-endocrine-candidiasis-ectodermal dystrophy. Eur J Pediatr (2009) 168:237-40. doi:10.1007/s00431-008-0736-8

11. Karner J, Meager A, Laan M, Maslovskaja J, Pihlap M, Remm A, et al. Anticytokine autoantibodies suggest pathogenetic links with autoimmune regulator deficiency in humans and mice. Clin Exp Immunol (2013) 171:263-72. doi:10.1111/cei.12024

12. Su MA, Davini D, Cheng P, Giang K, Fan U, DeVoss JJ, et al. Defective autoimmune regulator-dependent central tolerance to myelin protein zero is linked to autoimmune peripheral neuropathy. J Immunol (2012) 188:4906-12. doi:10.4049/jimmunol.1200493

13. Shum AK, DeVoss J, Tan CL, Hou Y, Johannes K, O’Gorman CS, et al. Identification of an autoantigen demonstrates a link between interstitial lung disease and a defect in central tolerance. Sci Transl Med (2009) 1:9ra20. doi:10.1126/scitranslmed.3000284 
14. Shum AK, Alimohammadi M, Tan CL, Cheng MH, Metzger TC, Law CS, et al. BPIFB1 is a lung-specific autoantigen associated with interstitial lung disease. Sci Transl Med (2013) 5:206ra139. doi:10.1126/scitranslmed.3006998

15. DeVoss J, Hou Y, Johannes K, Lu W, Liou GI, Rinn J, et al. Spontaneous autoimmunity prevented by thymic expression of a single self-antigen. $J$ Exp Med (2006) 203:2727-35. doi:10.1084/jem.20061864

16. Devoss JJ, Leclair NP, Hou Y, Grewal NK, Johannes KP, Lu W, et al. An autoimmune response to odorant binding protein la is associated with dry eye in the Aire-deficient mouse. J Immunol (2010) 184:4236-46. doi:10.4049/jimmunol. 0902434

17. Hou Y, DeVoss J, Dao V, Kwek S, Simko JP, McNeel DG, et al. An aberrant prostate antigen-specific immune response causes prostatitis in mice and is associated with chronic prostatitis in humans. JClin Invest (2009) 119:2031-41. doi:10.1172/JCI38332

18. Kuroda N, Mitani T, Takeda N, Ishimaru N, Arakaki R, Hayashi Y, et al. Development of autoimmunity against transcriptionally unrepressed target antigen in the thymus of Aire-deficient mice. J Immunol (2005) 174:1862-70.

19. Zhu ML, Nagavalli A, Su MA. Aire deficiency promotes TRP-1-specific immune rejection of melanoma. Cancer Res (2013) 73:2104-16. doi:10.1158/0008-5472. CAN-12-3781

20. Gavanescu I, Kessler B, Ploegh H, Benoist C, Mathis D. Loss of Aire-dependent thymic expression of a peripheral tissue antigen renders it a target of autoimmunity. Proc Natl Acad Sci U S A (2007) 104:4583-7. doi:10.1073/pnas. 0700259104

21. Kisand K, Peterson P. Autoimmune polyendocrinopathy candidiasis ectodermal dystrophy: known and novel aspects of the syndrome. Ann N Y Acad Sci (2011) 1246:77-91. doi:10.1111/j.1749-6632.2011.06308.x

22. Anderson MS, Venanzi ES, Chen Z, Berzins SP, Benoist C, Mathis D. The cellular mechanism of Aire control of T cell tolerance. Immunity (2005) 23:227-39. doi:10.1016/j.immuni.2005.07.005

23. Liston A, Gray DH, Lesage S, Fletcher AL, Wilson J, Webster KE, et al. Gene dosage - limiting role of Aire in thymic expression, clonal deletion, and organ-specific autoimmunity. J Exp Med (2004) 200:1015-26. doi:10.1084/ jem.20040581

24. Lambe T, Leung JC, Ferry H, Bouriez-Jones T, Makinen K, Crockford TL, et al. Limited peripheral $\mathrm{T}$ cell anergy predisposes to retinal autoimmunity. J Immunol (2007) 178:4276-83.

25. Gregerson DS, Heuss ND, Lehmann U, McPherson SW. Peripheral induction of tolerance by retinal antigen expression. J Immunol (2009) 183:814-22. doi:10.4049/jimmunol.0803748

26. Liston A, Lesage S, Wilson J, Peltonen L, Goodnow CC. Aire regulates negative selection of organ-specific T cells. Nat Immunol (2003) 4:350-4. doi:10.1038/ni906

27. Laan M, Peterson P. The many faces of Aire in central tolerance. Front Immunol (2013) 4:326. doi:10.3389/fimmu.2013.00326

28. Matsumoto M, Nishikawa Y, Nishijima H, Morimoto J, Matsumoto M, Mouri Y. Which model better fits the role of aire in the establishment of self-tolerance: the transcription model or the maturation model? Front Immunol (2013) 4:210. doi:10.3389/fimmu.2013.00210

29. Gillard GO, Dooley J, Erickson M, Peltonen L, Farr AG. Aire-dependent alterations in medullary thymic epithelium indicate a role for Aire in thymic epithelial differentiation. J Immunol (2007) 178:3007-15.

30. Milicevic Z, Milicevic NM, Laan M, Peterson P, Kisand K, Scott HS, et al. Ultrastructure of medullary thymic epithelial cells of autoimmune regulator (Aire)-deficient mice. Immunol Cell Biol (2010) 88:50-6. doi:10.1038/icb. 2009.55

31. Laan M, Kisand K, Kont V, Moll K, Tserel L, Scott HS, et al. Autoimmune regulator deficiency results in decreased expression of CCR4 and CCR7 ligands and in delayed migration of CD4+ thymocytes. J Immunol (2009) 183:7682-91. doi:10.4049/jimmunol.0804133

32. Li J, Li Y, Yao JY, Jin R, Zhu MZ, Qian XP, et al. Developmental pathway of CD4+CD8 - medullary thymocytes during mouse ontogeny and its defect in Aire-/- mice. Proc Natl Acad Sci U S A (2007) 104:18175-80. doi:10.1073/pnas.0708884104

33. Horai R, Silver PB, Chen J, Agarwal RK, Chong WP, Jittayasothorn Y, et al. Breakdown of immune privilege and spontaneous autoimmunity in mice expressing a transgenic $\mathrm{T}$ cell receptor specific for a retinal autoantigen. J Autoimmun (2013) 44:21-33. doi:10.1016/j.jaut.2013.06.003
34. Taniguchi RT, DeVoss JJ, Moon JJ, Sidney J, Sette A, Jenkins MK, et al. Detection of an autoreactive T-cell population within the polyclonal repertoire that undergoes distinct autoimmune regulator (Aire)-mediated selection. Proc Natl Acad Sci U S A (2012) 109:7847-52. doi:10.1073/pnas.1120607109

35. Fousteri G, Jasinski J, Dave A, Nakayama M, Pagni P, Lambolez F, et al. Following the fate of one insulin-reactive CD4 T cell: conversion into Teffs and Tregs in the periphery controls diabetes in NOD mice. Diabetes (2012) 61:1169-79. doi:10.2337/db11-0671

36. Klein L, Klugmann M, Nave KA, Tuohy VK, Kyewski B. Shaping of the autoreactive T-cell repertoire by a splice variant of self protein expressed in thymic epithelial cells. Nat Med (2000) 6:56-61. doi:10.1038/71540

37. Lambe T, Leung JC, Bouriez-Jones T, Silver K, Makinen K, Crockford TL, et al. CD4 T cell-dependent autoimmunity against a melanocyte neoantigen induces spontaneous vitiligo and depends upon Fas-Fas ligand interactions. J Immunol (2006) 177:3055-62.

38. Goodnow CC, Sprent J, Fazekas de St Groth B, Vinuesa CG. Cellular and genetic mechanisms of self tolerance and autoimmunity. Nature (2005) 435:590-7. doi:10.1038/nature03724

39. Teh CE, Daley SR, Enders A, Goodnow CC. T-cell regulation by casitas Blineage lymphoma (Cblb) is a critical failsafe against autoimmune disease due to autoimmune regulator (Aire) deficiency. Proc Natl Acad Sci U S A (2010) 107:14709-14. doi:10.1073/pnas.1009209107

40. Chappert P, Schwartz RH. Induction of T cell anergy: integration of environmental cues and infectious tolerance. Curr Opin Immunol (2010) 22:552-9. doi:10.1016/j.coi.2010.08.005

41. Steinman RM, Hawiger D, Liu K, Bonifaz L, Bonnyay D, Mahnke K, et al. Dendritic cell function in vivo during the steady state: a role in peripheral tolerance. Ann N Y Acad Sci (2003) 987:15-25. doi:10.1111/j.1749-6632.2003.tb06029.x

42. Kurts C, Heath WR, Kosaka H, Miller JF, Carbone FR. The peripheral deletion of autoreactive CD8+ T cells induced by cross-presentation of self-antigens involves signaling through CD95 (Fas, Apo-1). J Exp Med (1998) 188:415-20. doi:10.1084/jem.188.2.415

43. Barron L, Knoechel B, Lohr J, Abbas AK. Cutting edge: contributions of apoptosis and anergy to systemic T cell tolerance. J Immunol (2008) 180:2762-6.

44. Schietinger A, Delrow JJ, Basom RS, Blattman JN, Greenberg PD. Rescued tolerant CD8 T cells are preprogrammed to reestablish the tolerant state. Science (2012) 335:723-7. doi:10.1126/science.1214277

45. Wang G, Miyahara Y, Guo Z, Khattar M, Stepkowski SM, Chen W. "Default" generation of neonatal regulatory T cells. J Immunol (2010) 185:71-8. doi:10. 4049/jimmunol.0903806

46. King C, Ilic A, Koelsch K, Sarvetnick N. Homeostatic expansion of T cells during immune insufficiency generates autoimmunity. Cell (2004) 117:265-77. doi:10.1016/S0092-8674(04)00335-6

47. Knoechel B, Lohr J, Kahn E, Abbas AK. The link between lymphocyte deficiency and autoimmunity: roles of endogenous $\mathrm{T}$ and $\mathrm{B}$ lymphocytes in tolerance. J Immunol (2005) 175:21-6.

48. Guerau-de-Arellano M, Martinic M, Benoist C, Mathis D. Neonatal tolerance revisited: a perinatal window for Aire control of autoimmunity. $J$ Exp Med (2009) 206:1245-52. doi:10.1084/jem.20090300

49. Cohn M. Why Aire? Compensating for late bloomers. Eur J Immunol (2009) 39:2969-72. doi:10.1002/eji.200939628

50. Samy ET, Wheeler KM, Roper RJ, Teuscher C, Tung KS. Cutting edge: autoimmune disease in day 3 thymectomized mice is actively controlled by endogenous disease-specific regulatory T cells. J Immunol (2008) 180:4366-70.

51. Kojima A, Prehn RT. Genetic susceptibility to post-thymectomy autoimmune diseases in mice. Immunogenetics (1981) 14:15-27. doi:10.1007/BF00344296

52. Haneji N, Nakamura T, Takio K, Yanagi K, Higashiyama H, Saito I, et al. Identification of alpha-fodrin as a candidate autoantigen in primary Sjogren's syndrome. Science (1997) 276:604-7. doi:10.1126/science.276.5312.604

53. Jiang W, Anderson MS, Bronson R, Mathis D, Benoist C. Modifier loci condition autoimmunity provoked by Aire deficiency. J Exp Med (2005) 202:805-15. doi:10.1084/jem.20050693

54. Sakaguchi S, Takahashi T, Nishizuka Y. Study on cellular events in postthymectomy autoimmune oophoritis in mice. I. Requirement of Lyt-1 effector cells for oocytes damage after adoptive transfer. J Exp Med (1982) 156:1565-76. doi:10.1084/jem.156.6.1565

55. Sakaguchi S, Sakaguchi N. Thymus and autoimmunity: capacity of the normal thymus to produce pathogenic self-reactive $\mathrm{T}$ cells and conditions required 
for their induction of autoimmune disease. J Exp Med (1990) 172:537-45. doi:10.1084/jem.172.2.537

56. Datta S, Sarvetnick N. Lymphocyte proliferation in immune-mediated diseases. Trends Immunol (2009) 30:430-8. doi:10.1016/j.it.2009.06.002

57. Asano M, Toda M, Sakaguchi N, Sakaguchi S. Autoimmune disease as a consequence of developmental abnormality of a T cell subpopulation. J Exp Med (1996) 184:387-96. doi:10.1084/jem.184.2.387

58. Davalos-Misslitz AC, Worbs T, Willenzon S, Bernhardt G, Forster R. Impaired responsiveness to $\mathrm{T}$-cell receptor stimulation and defective negative selection of thymocytes in CCR7-deficient mice. Blood (2007) 110:4351-9. doi:10.1182/ blood-2007-01-070284

59. Kurobe H, Liu C, Ueno T, Saito F, Ohigashi I, Seach N, et al. CCR7-dependent cortex-to-medulla migration of positively selected thymocytes is essential for establishing central tolerance. Immunity (2006) 24:165-77. doi:10.1016/ j.immuni.2005.12.011

60. Ueno T, Saito F, Gray DH, Kuse S, Hieshima K, Nakano H, et al. CCR7 signals are essential for cortex-medulla migration of developing thymocytes. $J$ Exp Med (2004) 200:493-505. doi:10.1084/jem.20040643

61. Surh CD, Sprent J. Homeostasis of naive and memory T cells. Immunity (2008) 29:848-62. doi:10.1016/j.immuni.2008.11.002

62. Sprent J, Surh CD. Normal T cell homeostasis: the conversion of naive cells into memory-phenotype cells. Nat Immunol (2011) 12:478-84. doi:10.1038/ni.2018

63. Calzascia T, Pellegrini M, Lin A, Garza KM, Elford AR, Shahinian A, et al. CD4 T cells, lymphopenia, and IL-7 in a multistep pathway to autoimmunity. Proc Natl Acad Sci U S A (2008) 105:2999-3004. doi:10.1073/pnas.0712135105

64. Le Campion A, Gagnerault MC, Auffray C, Becourt C, Poitrasson-Riviere M, Lallemand E, et al. Lymphopenia-induced spontaneous T-cell proliferation as a cofactor for autoimmune disease development. Blood (2009) 114:1784-93. doi:10.1182/blood-2008-12-192120

65. Goronzy JJ, Li G, Yang Z, Weyand CM. The janus head of T cell aging autoimmunity and immunodeficiency. Front Immunol (2013) 4:131. doi:10. 3389/fimmu.2013.00131

66. Deshpande P, Cavanagh MM, Le Saux S, Singh K, Weyand CM, Goronzy JJ. IL-7- and IL-15-mediated TCR sensitization enables T cell responses to selfantigens. J Immunol (2013) 190:1416-23. doi:10.4049/jimmunol.1201620

67. Ramsey C, Winqvist O, Puhakka L, Halonen M, Moro A, Kampe O, et al. Aire deficient mice develop multiple features of APECED phenotype and show altered immune response. Hum Mol Genet (2002) 11:397-409. doi:10.1093/ $\mathrm{hmg} / 11.4 .397$

68. Anderson MS, Venanzi ES, Klein L, Chen Z, Berzins SP, Turley SJ, et al. Projection of an immunological self shadow within the thymus by the aire protein. Science (2002) 298:1395-401. doi:10.1126/science.1075958

69. Kekalainen E, Lehto MK, Smeds E, Miettinen A, Meri S, Jarva H, et al. Defective central tolerance in Aire-deficient mice is not sufficient to induce symptomatic autoimmunity during lymphopenia-induced $\mathrm{T}$ cell proliferation. Scand J Immunol (2011) 74:71-9. doi:10.1111/j.1365-3083.2011.02543.x

70. Forrester JV, Xu H. Good news-bad news: the Yin and Yang of immune privilege in the eye. Front Immunol (2012) 3:338. doi:10.3389/fimmu.2012.00338

71. Forrester JV, Xu H, Lambe T, Cornall R. Immune privilege or privileged immunity? Mucosal Immunol (2008) 1:372-81. doi:10.1038/mi.2008.27

72. Caspi RR. A look at autoimmunity and inflammation in the eye. J Clin Invest (2010) 120:3073-83. doi:10.1172/JCI42440

73. Breunig A, Lee MS, Miller BS, Binstadt BA, Anderson MS, Montezuma S. Autoimmune retinopathy in a patient with autoimmune polyendocrine syndrome type I. Ocul Immunol Inflamm (2013) 21:153-7. doi:10.3109/09273948. 2012.754906

74. Chen J, Qian H, Horai R, Chan CC, Falick Y, Caspi RR. Comparative analysis of induced vs. spontaneous models of autoimmune uveitis targeting the interphotoreceptor retinoid binding protein. PLoS One (2013) 8:e72161. doi:10.1371/journal.pone.0072161

75. Takeuchi M, Keino H, Kezuka T, Usui M, Taguchi O. Immune responses to retinal self-antigens in $\mathrm{CD} 25(+) \mathrm{CD} 4(+)$ regulatory T-cell-depleted mice. Invest Ophthalmol Vis Sci (2004) 45:1879-86. doi:10.1167/iovs.02-1030

76. McPherson SW, Heuss ND, Gregerson DS. Lymphopenia-induced proliferation is a potent activator for $\mathrm{CD} 4+\mathrm{T}$ cell-mediated autoimmune disease in the retina. J Immunol (2009) 182:969-79.

77. Gonzalez-Fernandez F. Interphotoreceptor retinoid binding protein; myths and mysteries. J Ophthalmic Vis Res (2012) 7:100-4.
78. Fan Y, Rudert WA, Grupillo M, He J, Sisino G, Trucco M. Thymus-specific deletion of insulin induces autoimmune diabetes. EMBO J (2009) 28:2812-24. doi:10.1038/emboj.2009.212

79. Aichinger M, Hinterberger M, Klein L. Probing gene function in thymic epithelial cells. Eur J Cell Biol (2012) 91:24-30. doi:10.1016/j.ejcb.2011.01.005

80. Kay TW, Krishnamurthy B, Brodnicki TC, Mannering SI. Insulin teaches a new lesson in tolerance. EMBO J (2009) 28:2687-8. doi:10.1038/emboj.2009.251

81. Leroux L, Desbois P, Lamotte L, Duvillie B, Cordonnier N, Jackerott M, et al. Compensatory responses in mice carrying a null mutation for Ins1 or Ins2. Diabetes (2001) 50(Suppl 1):S150-3. doi:10.2337/diabetes.50.2007.S150

82. Niki S, Oshikawa K, Mouri Y, Hirota F, Matsushima A, Yano M, et al. Alteration of intra-pancreatic target-organ specificity by abrogation of Aire in NOD mice. J Clin Invest (2006) 116:1292-301. doi:10.1172/JCI26971

83. Paolino M, Penninger JM. Cbl-b in T-cell activation. Semin Immunopathol (2010) 32:137-48. doi:10.1007/s00281-010-0197-9

84. Hoyne GF, Flening E, Yabas M, Teh C, Altin JA, Randall K, et al. Visualizing the role of Cbl-b in control of islet-reactive CD4 T cells and susceptibility to type 1 diabetes. J Immunol (2011) 186:2024-32. doi:10.4049/jimmunol. 1002296

85. Vanasek TL, Nandiwada SL, Jenkins MK, Mueller DL. CD25+Foxp3+ regulatory $\mathrm{T}$ cells facilitate $\mathrm{CD} 4+\mathrm{T}$ cell clonal anergy induction during the recovery from lymphopenia. J Immunol (2006) 176:5880-9.

86. Mingueneau M, Jiang W, Feuerer M, Mathis D, Benoist C. Thymic negative selection is functional in NOD mice. J Exp Med (2012) 209:623-37. doi:10.1084/jem.20112593

87. Pauken KE, Linehan JL, Spanier JA, Sahli NL, Kalekar LA, Binstadt BA, et al. Cutting edge: type 1 diabetes occurs despite robust anergy among endogenous insulin-specific CD4 T cells in NOD mice. J Immunol (2013) 191:4913-7. doi:10.4049/jimmunol.1301927

88. Gagnerault MC, Lanvin O, Pasquier V, Garcia C, Damotte D, Lucas B, et al. Autoimmunity during thymectomy-induced lymphopenia: role of thymus ablation and initial effector $\mathrm{T}$ cell activation timing in nonobese diabetic mice. J Immunol (2009) 183:4913-20. doi:10.4049/jimmunol.0901954

89. Alferink J, Tafuri A, Vestweber D, Hallmann R, Hammerling GJ, Arnold B. Control of neonatal tolerance to tissue antigens by peripheral $\mathrm{T}$ cell trafficking. Science (1998) 282:1338-41. doi:10.1126/science.282.5392.1338

90. Kuma A, Hatano M, Matsui M, Yamamoto A, Nakaya H, Yoshimori T, et al. The role of autophagy during the early neonatal starvation period. Nature (2004) 432:1032-6. doi:10.1038/nature03029

91. Kekalainen E, Tuovinen H, Joensuu J, Gylling M, Franssila R, Pontynen $\mathrm{N}$, et al. A defect of regulatory $\mathrm{T}$ cells in patients with autoimmune polyendocrinopathy-candidiasis-ectodermal dystrophy. J Immunol (2007) 178:1208-15.

92. Laakso SM, Laurinolli TT, Rossi LH, Lehtoviita A, Sairanen H, Perheentupa J, et al. Regulatory $\mathrm{T}$ cell defect in APECED patients is associated with loss of naive FOXP3 $(+)$ precursors and impaired activated population. J Autoimmun (2010) 35:351-7. doi:10.1016/j.jaut.2010.07.008

93. Ryan KR, Lawson CA, Lorenzi AR, Arkwright PD, Isaacs JD, Lilic D. CD4+CD25+ T-regulatory cells are decreased in patients with autoimmune polyendocrinopathy candidiasis ectodermal dystrophy. J Allergy Clin Immunol (2005) 116:1158-9. doi:10.1016/j.jaci.2005.08.036

94. Wolff AS, Oftedal BE, Kisand K, Ersvaer E, Lima K, Husebye ES. Flow cytometry study of blood cell subtypes reflects autoimmune and inflammatory processes in autoimmune polyendocrine syndrome type I. Scand J Immunol (2010) 71:459-67. doi:10.1111/j.1365-3083.2010.02397.x

95. Pitt LA, Hubert FX, Scott HS, Godfrey DI, Berzins SP. NKT cell development in the absence of the autoimmune regulator gene (Aire). Eur J Immunol (2008) 38:2689-96. doi:10.1002/eji.200838553

96. Malchow S, Leventhal DS, Nishi S, Fischer BI, Shen L, Paner GP, et al. Airedependent thymic development of tumor-associated regulatory T cells. Science (2013) 339:1219-24. doi:10.1126/science.1233913

97. Lei Y, Ripen AM, Ishimaru N, Ohigashi I, Nagasawa T, Jeker LT, et al. Airedependent production of XCL1 mediates medullary accumulation of thymic dendritic cells and contributes to regulatory T cell development. J Exp Med (2011) 208:383-94. doi:10.1084/jem.20102327

98. Altin JA, Tian L, Liston A, Bertram EM, Goodnow CC, Cook MC. Decreased T-cell receptor signaling through CARD11 differentially compromises forkhead box protein 3-positive regulatory versus $\mathrm{T}(\mathrm{H}) 2$ effector cells to cause 
allergy. JAllergy Clin Immunol (2011) 127(1277-85):e5. doi:10.1016/j.jaci.2010. 12.1081

99. Chen Z, Benoist C, Mathis D. How defects in central tolerance impinge on a deficiency in regulatory T cells. Proc Natl Acad Sci U S A (2005) 102:14735-40. doi:10.1073/pnas.0507014102

100. Ziegler SF. FOXP3: of mice and men. Annu Rev Immunol (2006) 24:209-26. doi:10.1146/annurev.immunol.24.021605.090547

101. Mayer CT, Tian L, Hesse C, Kuhl AA, Swallow M, Kruse F, et al. Anti-CD4 treatment inhibits autoimmunity in scurfy mice through the attenuation of co-stimulatory signals. J Autoimmun (2013). doi:10.1016/j.jaut.2013.08.010

102. Zhang N, Bevan MJ. TGF-beta signaling to $\mathrm{T}$ cells inhibits autoimmunity during lymphopenia-driven proliferation. Nat Immunol (2012) 13:667-73. doi:10.1038/ni.2319

103. Kisand K, Lilic D, Casanova JL, Peterson P, Meager A, Willcox N. Mucocutaneous candidiasis and autoimmunity against cytokines in APECED and thymoma patients: clinical and pathogenetic implications. Eur J Immunol (2011) 41:1517-27. doi:10.1002/eji.201041253

104. Chang C. Neonatal autoimmune diseases: a critical review. JAutoimmun (2012) 38:J223-38. doi:10.1016/j.jaut.2011.11.018

105. Comans-Bitter WM, de Groot R, van den Beemd R, Neijens HJ, Hop WC, Groeneveld K, et al. Immunophenotyping of blood lymphocytes in childhood. Reference values for lymphocyte subpopulations. J Pediatr (1997) 130:388-93. doi:10.1016/S0022-3476(97)70200-2

106. Laakso SM, Kekalainen E, Rossi LH, Laurinolli TT, Mannerstrom H, Heikkila N, et al. IL-7 dysregulation and loss of CD8+ T cell homeostasis in the monogenic human disease autoimmune polyendocrinopathy-candidiasis-ectodermal dystrophy. J Immunol (2011) 187:2023-30. doi:10.4049/jimmunol.1100212

107. Kisand K, Boe Wolff AS, Podkrajsek KT, Tserel L, Link M, Kisand KV, et al. Chronic mucocutaneous candidiasis in APECED or thymoma patients correlates with autoimmunity to Th17-associated cytokines. J Exp Med (2010) 207:299-308. doi:10.1084/jem.20091669

108. Wolff AS, Sarkadi AK, Marodi L, Karner J, Orlova E, Oftedal BE, et al. Anticytokine autoantibodies preceding onset of autoimmune polyendocrine syndrome type I features in early childhood. J Clin Immunol (2013) 33:1341-8. doi:10.1007/s10875-013-9938-6

109. Shiono H, Wong YL, Matthews I, Liu JL, Zhang W, Sims G, et al. Spontaneous production of anti-IFN-alpha and anti-IL-12 autoantibodies by thymoma cells from myasthenia gravis patients suggests autoimmunization in the tumor. Int Immunol (2003) 15:903-13. doi:10.1093/intimm/dxg088

Conflict of Interest Statement: The authors declare that the research was conducted in the absence of any commercial or financial relationships that could be construed as a potential conflict of interest.

Received: 03 December 2013; paper pending published: 23 December 2013; accepted: 29 January 2014; published online: 13 February 2014.

Citation: Kisand K, Peterson P and Laan M (2014) Lymphopenia-induced proliferation in Aire-deficient mice helps to explain their autoimmunity and differences from human patients. Front. Immunol. 5:51. doi: 10.3389/fimmu.2014.00051

This article was submitted to T Cell Biology, a section of the journal Frontiers in Immunology.

Copyright (C) 2014 Kisand, Peterson and Laan. This is an open-access article distributed under the terms of the Creative Commons Attribution License (CC BY). The use, distribution or reproduction in other forums is permitted, provided the original author(s) or licensor are credited and that the original publication in this journal is cited, in accordance with accepted academic practice. No use, distribution or reproduction is permitted which does not comply with these terms. 